\title{
A Cytomorphometric Study of Cervical Cancer and Pre-Cancer with Bacterial Morphometry in West Bengal with Special Reference to Midnapore District
}

\author{
Agniva Misra $^{1}$, Suman Chakraborty ${ }^{2}$, Aurobindo Routray ${ }^{3}$ \\ ${ }^{1}$ Advanced Technology Development Centre, IIT, Kharagpur \\ ${ }^{2}$ Mechanical Engineering Department, IIT, Kharagpur \\ ${ }^{3}$ Electrical Engineering Department, IIT, Kharagpur
}

\begin{abstract}
The purpose of this study was to measure some cytomorphometric parameters in different female uterine cervical conditions to study the progression of pathology from normal to neoplastic conditions. Using a computerised cytomorphometric cellmeasurement pro- gram, the study was based on a cross sectional study of smear cases diagnosed with different uterine cervical conditions from 2012 to 2014.From different kinds of microscopic image ( bright field microscopy), 100 pictures of normal cells and 100 pictures of pathological cells are selected. Then some cytoplasmic and nuclear parameters(Area, Perimeter, Convex area, Eccentricity, Major axis length, Minor axis length, Equivalent diameter) are assessed. All the parameters(Area,Convex area,perimeter,major axis length,minor axis length,equivalent diameter) are lowest in neoplasia,highest in hypertrophied cervix. Area and convex areas are lowest in hypertrophied cervix and neoplasia,highest in dysplasia.Perimeter,major axis length,equivalent diameters are lowest in hypertrophied cervix, highest in dysplasia.Minor axis length is lowest in neoplasia,highest in dysplasia.Among bacterial cytomorphometric parameters, area,convex area,perimeter,major axis length,equivalent diameters are lowest in normal, highest in dysplasia.Minor axis length is lowest in normal,highest in hypertrophied cervix and neoplasia.
\end{abstract}

\section{Introduction}

Cervical cancer (CC) is the 2nd most common cause of cancer death among women globally. Worldwide, out of 7.6 million cancer deaths, $3.6 \%$ was due to CC in 2008 and out of 12.7 million new cancer cases, $4.2 \%$ were CC in 2008 and $84 \%$ of it occurs in less developed countries.(1)

One of the most important achievements of modern medicine was to understand the pathogenesis of cervical cancer, that is its development from precursor lesions, the cervical intraepithelial neoplasia, CIN. Precursor lesions occur almost exclusive in women that had sexual relationships, the association between cervical carcinoma and sexual activity being known for more than 150 years.

Sexual life and promiscuity are markers of high relative risk for causing cervical lesions by the increased risk of achieving an oncogenic factor,(Human Papillomavirus, HPV) in the majority of cases.

It should be mentioned that $80 \%$ of cervical cancers occur in women from underdeveloped countries. Screening programs using Papanicolaou (Pap) smear test have reduced significantly the number of invasive cancers, by early diagnosis and treatment of precancerous lesions, the cervical intraepithelial neoplasia, CIN.

The period of time necessary for an intraepithelial lesion to transform into an invasive carcinoma varies from a few months to a few years, depending on the tumors aggressivity and the host specific resistance. Due to the slow progression of this disease, cervical cancer may be diagnosed in early stages of intraepithelial lesion.

When precancerous lesions are diagnosed before their progression towards a cancerous lesion, by applying early therapeutical measures adequate for each stage, the rate of survival may reach almost $100 \%$. Thus, prognosis in invasive cancer depends on the stage of diagnosed precancerous lesion.

Anatomo-pathological studies, through histopathological and morphological methods still have an important role in establishing the prognostic factors in cervical cancer, and implicit decisive role in developing early diagnosis methods for an efficient treatment of cervical cancer.

In this context, for histopathological evaluation of cervical tumors a series of quantitative pathology techniques have been used, like morphometric and stereological measurements, that together with conventional, histopathological or semiquantitative (grading), descriptive methods permitted an approach of these prognostic factors.(2)

Cytomorphometry is a quantitative technique to measure the cells of interest in different conditions. It is useful to classify the different disease condition by calculating different cellular parameters e.g. Area, Perimeter, Convex area, Eccentricity, Major axis length, Minor axis length, Equivalent diameter, Compactness, Mean RGB value, Minimum RGB value, Maximum RGB value, Standard deviation of RGB value, Entropy of 
RGB value, Cooc features(Stats,contrast,stats,correlation,stats,energy,stats,homogeneity). Here it is done on cervical smear through DIC, Phase contrast, Bright field microscopy of PAP stain to understand the progression of pathology from normal to neoplastic condition (e.g. normal, cervicitis, hypertrophied cervix, dysplasia, neoplasia etc.).

\subsection{Polysol Preservation Solution Preparation:}

\section{Materials and methods}

Polysol is a preservative solution which is used for preserving the biological sample. Here We have used the following ingredients( $\mathrm{NaCl}-4.96 \mathrm{gm}$, sodium acetate-7.48 gm, KCl-0.74 gm,calcium chloride-0.368 gm,magnesium chloride-0.305 gm). These ingredients were dissolved into 1 litre of distilled water and a small portion of liquefied phenol was dissolved into it. Polysol has $\mathrm{pH}$ of 7.4 . (3)

\subsection{Sample Collection Method:}

Sample was collected from 80 outdoor patients in Midnapore medical college and hospital. Patient was in the lithotomy position Sample was collected by circular motion of tip of Ayre's spatula and the cells from each patient were dissolved into $5 \mathrm{ml}$. of polysol solution in a Eppendorf's tube. Then sample was carried to IIT,Kharagpur.

\subsection{Method For Pap Staining :}

$5 \mathrm{ml}$. of polysol containing cervical cells was taken for exfoliative cytology.Sample is centrifuged. Supernatant is discarded and some amount of polysol is given to it.Vortexing and Funneling is done again. 500 microlitre of sample was given into funnel and again centrifugation is done .Supernatant is discarded and fixation was done for 10 minutes with $95 \%$ propanol.supernatant was discarded and slide was put into alcohol.Slide was airdried.Isopropyl alcohol was given into the slide and it was kept for 10-15 minutes.Alcohol washing was done.Sample was washed under tap water for 1-2 minutes.Harris haema stain was given to sample and kept for 2 mnts.Washing was done with tap water for 3-5 minutes.Slide was rinsed with $1 \%$ acid alcohol. Again washing was done with tap water for 5-15 mnts.OG-6 was given for 2 mnts. and water-washing was done. Isopropyl alcohol was given for 2 mnts. and water-washing was done. EA-50 was given for 4 mnts. and water-washing was done.Isopropyl alcohol was given for 2-3 mnts. water-washing was done. Sample was dried and Xylene was given to it.Sample was dried and mounting was done with DPX. Sample was examined under Microscope.(4)

\subsection{Principle of Bright Field Microscopy :}

Bright-field microscopy is the simplest of all the optical microscopy illumination techniques. Sample illumination is transmitted (i.e., illuminated from below and observed from above) white light and contrast in the sample is caused by absorbance of some of the transmitted light in dense areas of the sample. Bright-field microscopy is the simplest of a range of techniques used for illumination of samples in light microscopes and its simplicity makes it a popular technique. The typical appearance of a bright-field microscopy image is a dark sample on a bright background, hence the name.(5)

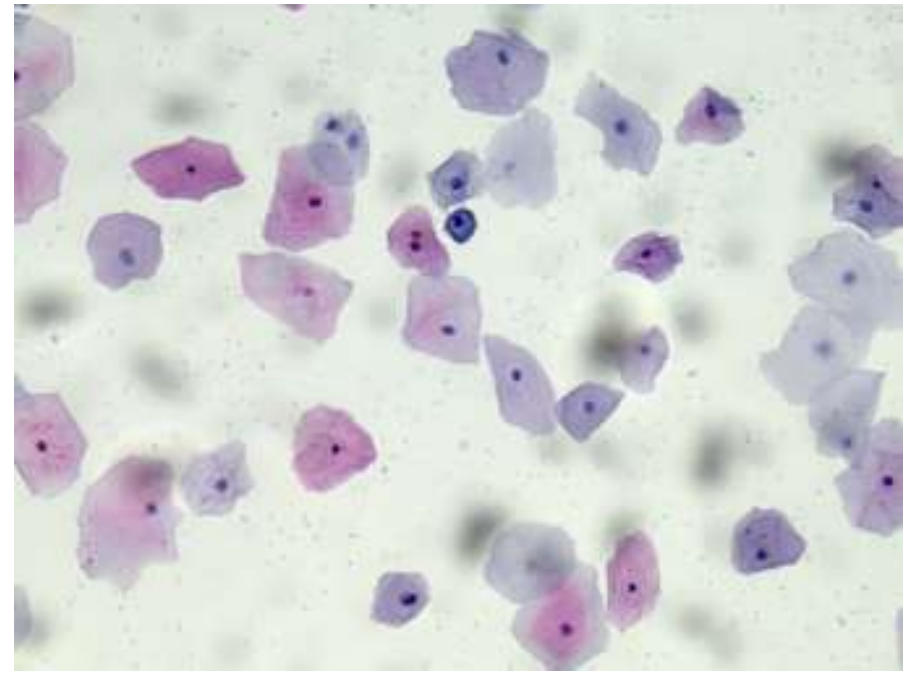

Figure 1: Sample picture of Pap stained image 


\subsection{Diagnosis Of Disease From Image:}

Diagnosis was made for the bright field image of pap stained smear by expert cytopathologists.

\subsection{Image Analysis :}

100 images of normal smear and 100 images of pathological smear are selected. Part of images containing cells of interest were cut out by microsoft paint and they were named accordingly( cell-normal1,cell-cervicitis-1,cell-hypertrophied cervix-1,cell-dysplasia-1,cell-neoplasia-1 etc.). Pixel values of the region of interest were calculated and they were recorded in a file. Cells of interest(cervical cells and bacteria ) are segmented by watershed segmentation and some cellular parameters(area,convex area, perimeter,major axis length,minor axis length,equivalent diameter etc.) were calculated in pixel values. Pixel values are converted into micrometer unit using the above mentioned file after correlating the data with conventional medical knowledge .

\section{Result and Discussion}

We have got the following results. It will describe the numerical values of cellular parameters for different diseases. Area and convex area will be expressed in square of micrometer unit. Perimeter,major axis length,minor axis length,equivalent diameter will be expressed in micrometer unit.

\section{Chart 1: Cellular areas for different cervical conditions(in $\left.\mu^{2}{ }^{2}\right)$}

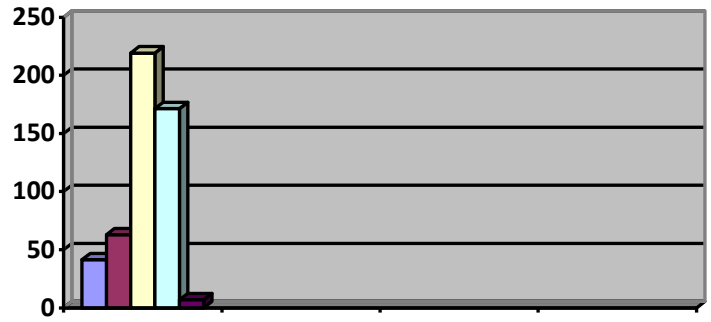

\begin{tabular}{|l}
$\square$ Normal \\
$\square$ Cervicitis \\
$\square$ Hypertrophied cervix \\
$\square$ Dysplasia \\
$\square$ Neoplasia
\end{tabular}

Chart 2: Nuclear areas for different cervical conditions(in $\left.\mu \mathrm{m}^{2}\right)$

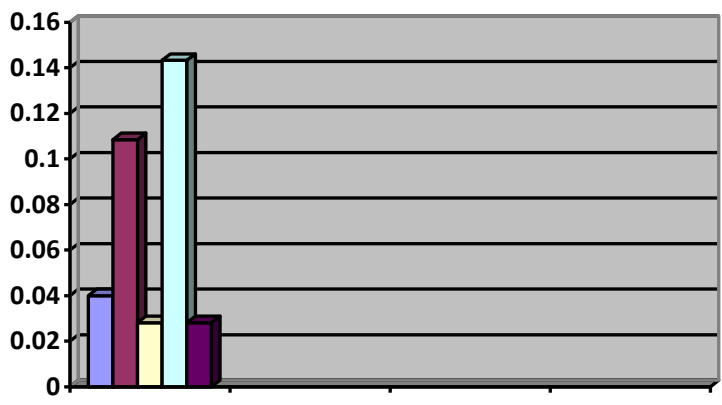

\begin{tabular}{|l|}
\hline Normal \\
$\square$ cervicitis \\
$\square$ Hypertrophied cervix \\
$\square$ Dysplasia \\
$\square$ Neoplasia
\end{tabular}

Chart 3: Cellular convex areas for different cervical conditions(in $\left.\mu \mathrm{m}^{2}\right)$

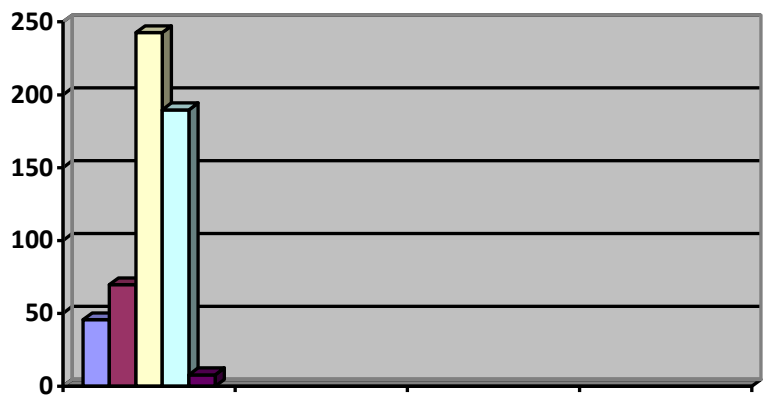

\begin{tabular}{|l|}
$\square$ Normal \\
$\square$ Cervicitis \\
$\square$ Hypertrophied cervix \\
$\square$ Dysplasia \\
$\square$ Neoplasia
\end{tabular}

Chart 4: Nuclear convex areas for different cervical conditions(in $\left.\mu \mathrm{m}^{2}\right)$ 

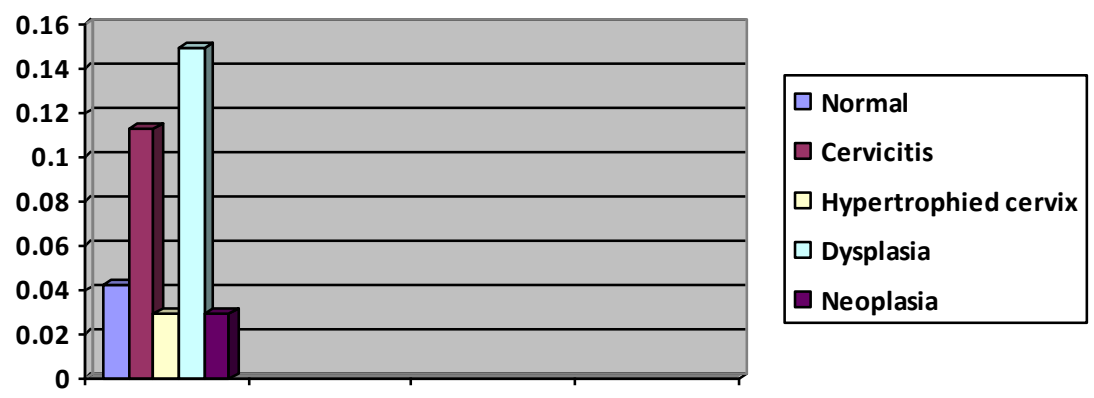

Chart 5: Cellular perimeters for different cervical conditions(in $\mu \mathrm{m})$

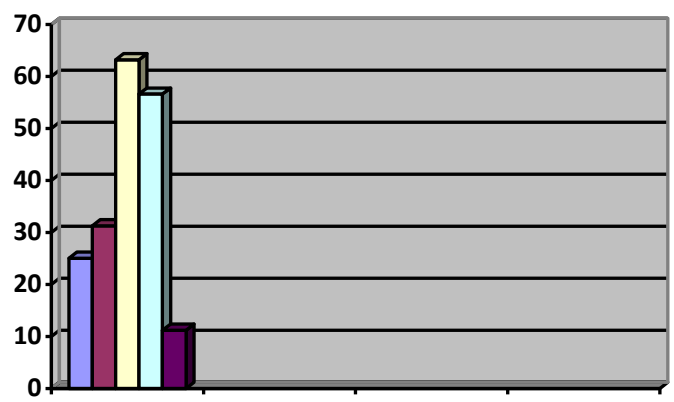

\begin{tabular}{|l|}
$\square$ Normal \\
$\square$ Cervicitis \\
$\square$ Hypertrophied cervix \\
$\square$ Dysplasia \\
$\square$ Neoplasia
\end{tabular}

Chart 6: Nuclear perimeters for different cervical conditions(in $\mu \mathrm{m})$

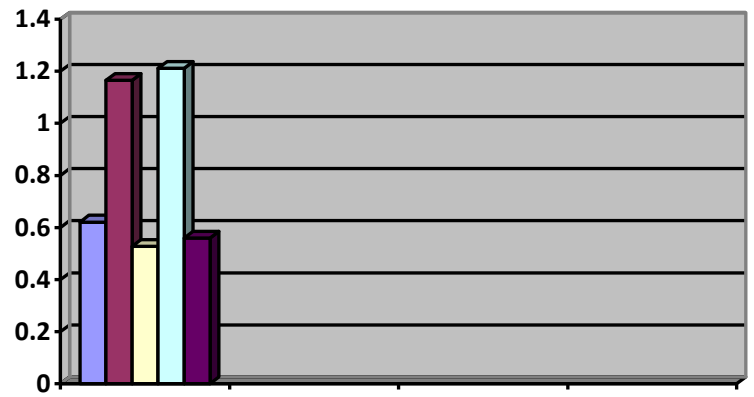

\begin{tabular}{|l|}
$\square$ Normal \\
$\square$ Cervicitis \\
$\square$ Hypertrophied cervix \\
$\square$ Dysplasia \\
$\square$ neoplasia
\end{tabular}

Chart 7: Cellular major axis lengths for different cervical conditions(in $\mu \mathrm{m})$

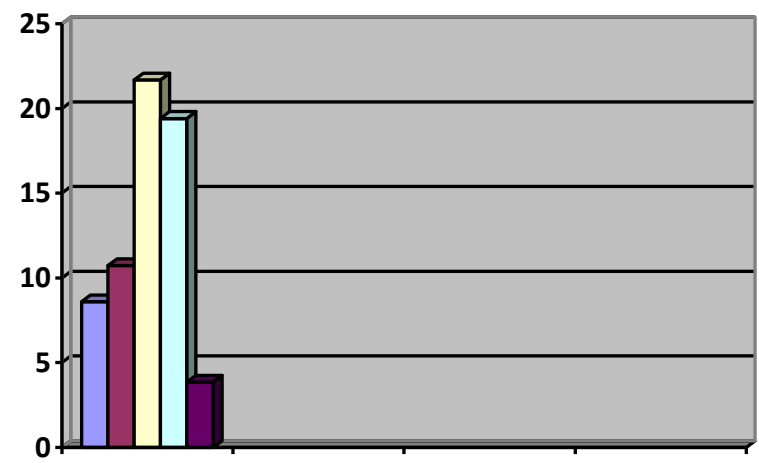

\begin{tabular}{|l|}
\hline Normal \\
$\square$ Cervicitis \\
$\square$ Hypertrophied cervix \\
$\square$ dysplasia \\
$\square$ Neoplasia \\
\hline
\end{tabular}

Chart 8: Nuclear major axis lengths for different cervical conditions (in $\mu \mathrm{m}$ ) 


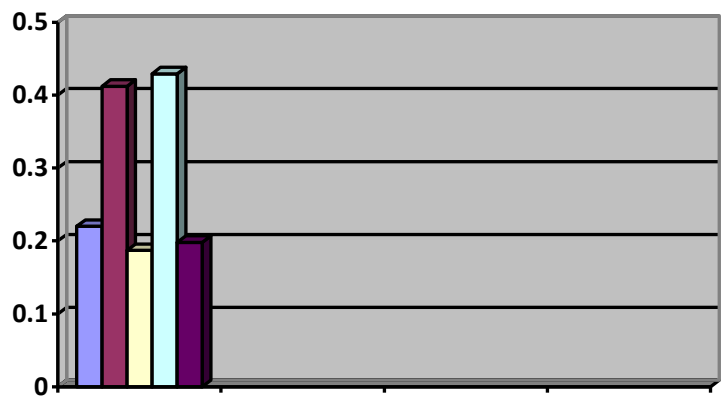

\begin{tabular}{|l}
$\square$ Normal \\
$\square$ Cervicitis \\
$\square$ hypertrophied cervix \\
$\square$ Dysplasia \\
$\square$ Neoplasia
\end{tabular}

Chart 9: Cellular minor axis lengths for different cervical conditions(in $\mu \mathrm{m})$

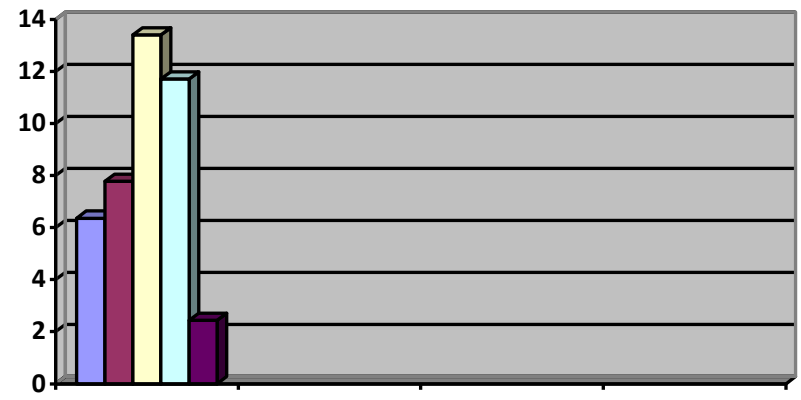

\begin{tabular}{|l|}
$\square$ Normal \\
$\square$ Cervicitis \\
$\square$ Hypertrophied cervix \\
$\square$ Dysplasia \\
$\square$ Neoplasia
\end{tabular}

Chart 10: Nuclear minor axis lengths for different cervical conditions(in $\mu \mathrm{m})$

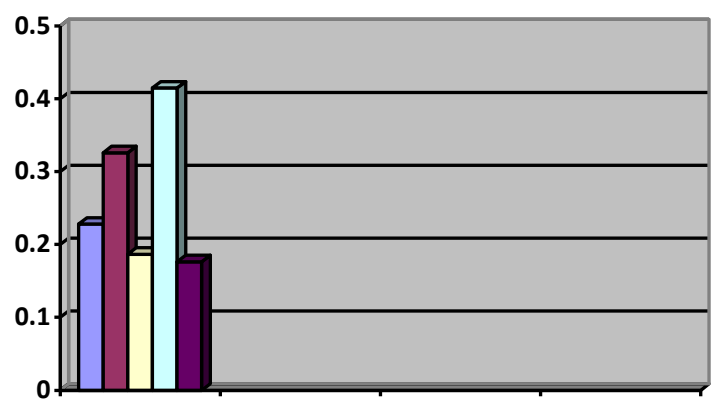

\begin{tabular}{|l|}
$\square$ Normal \\
$\square$ Cervicitis \\
$\square$ Hypertrophied cervix \\
$\square$ Dysplasia \\
$\square$ Neoplasia
\end{tabular}

Chart 11: Cellular equivalent diameters for different cervical conditions(in $\mu \mathrm{m})$

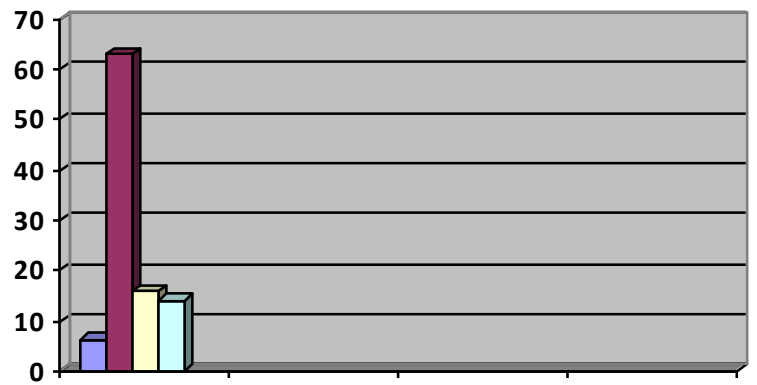

\begin{tabular}{|l|}
\hline Normal \\
$\square$ Cervicitis \\
$\square$ Hypertrophied cervix \\
$\square$ Dysplasia \\
$\square$ Neoplasia
\end{tabular}

Chart 12: Nuclear equivalent diameters for different cervical conditions (in $\mu \mathrm{m}$ ) 


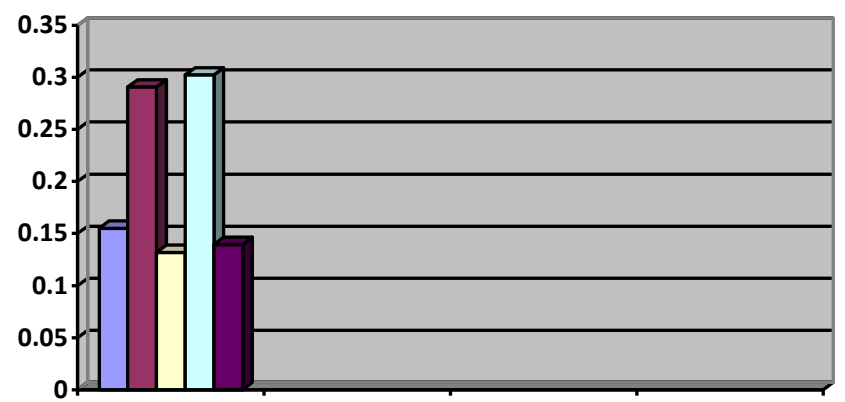

\begin{tabular}{|l|}
$\square$ Normal \\
$\square$ Cervicitis \\
$\square$ Hypertrophied cervix \\
$\square$ Dysplasia \\
$\square$ Neoplasia \\
\hline
\end{tabular}

Chart 13: Bacterial areas for different cervical conditions(in $\left.\mu \mathrm{m}^{2}\right)$

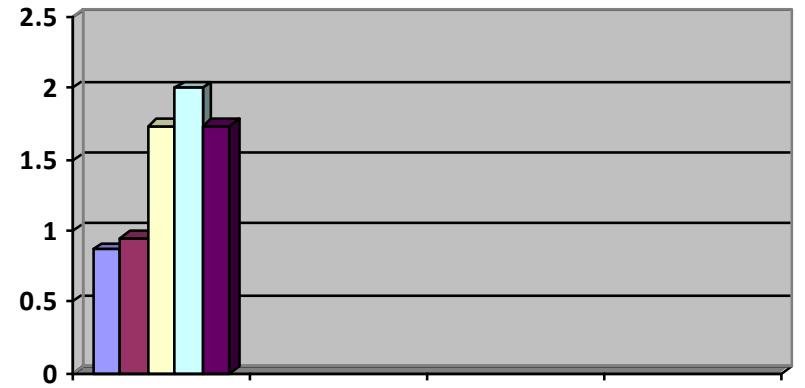

\begin{tabular}{|l|}
\hline Normal \\
$\square$ Cervicitis \\
$\square$ Hypertrophied cervix \\
$\square$ Dysplasia \\
$\square$ Neoplasia
\end{tabular}

Chart 14: Bacterial convex areas for different cervical conditions $\left(\right.$ in $\left.\mu \mathrm{m}^{2}\right)$

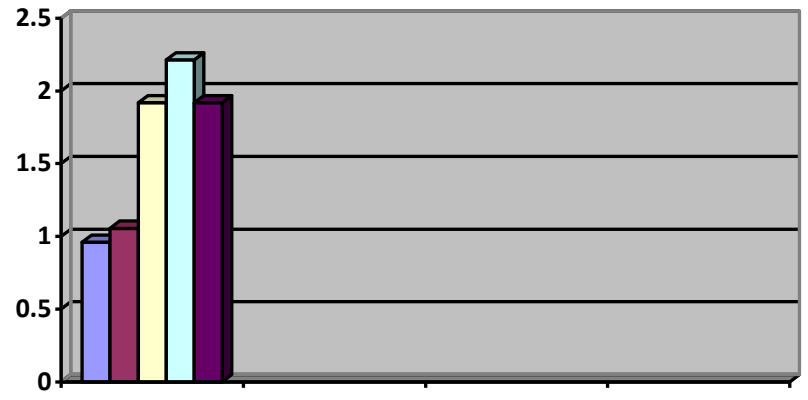

\begin{tabular}{|l|}
\hline Normal \\
$\square$ Cervicitis \\
$\square$ Hypertrophied cervix \\
$\square$ Dysplasia \\
$\square$ Neoplasia
\end{tabular}

Chart 15: Bacterial perimeters for different cervical conditions(in $\mu \mathrm{m})$

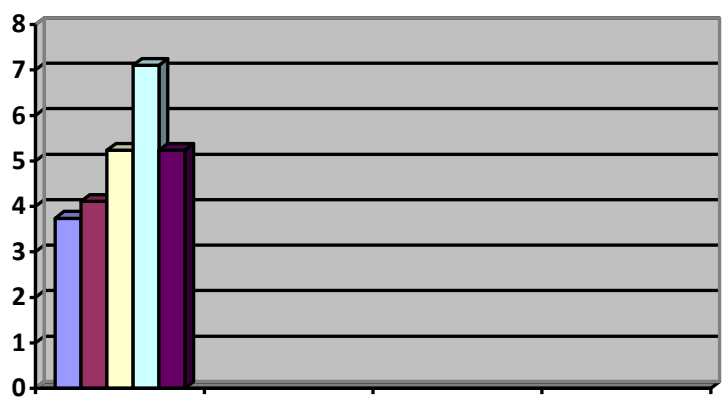

$\square$ Neoplasia

Chart 16 : Bacterial major axis lengths for different cervical conditions(in $\mu \mathrm{m})$ 


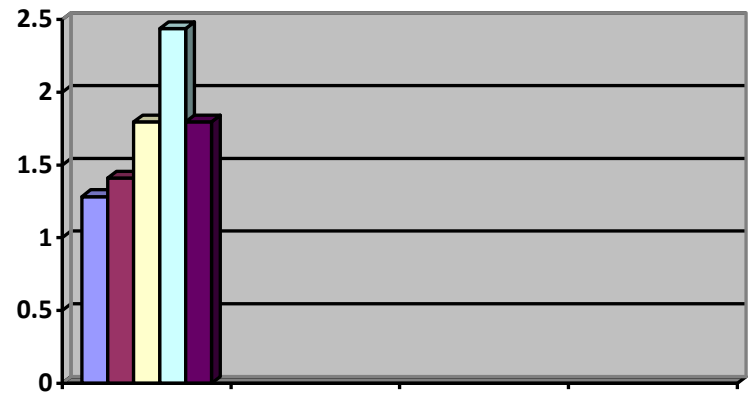

\begin{tabular}{|l|}
\hline Normal \\
$\square$ Cervicitis \\
$\square$ Hypertrophied cervix \\
$\square$ Dysplasia \\
$\square$ Neoplasia \\
\hline
\end{tabular}

Chart 17: Bacterial minor axis lengths for different cervical conditions(in $\mu \mathrm{m})$

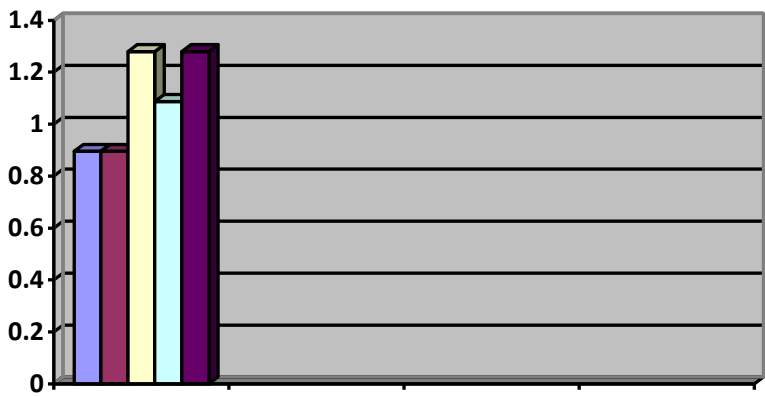

\begin{tabular}{|l|}
$\square$ Normal \\
$\square$ Cervicitis \\
$\square$ Hypertrophied cervix \\
$\square$ Dysplasia \\
$\square$ Neoplasia
\end{tabular}

Chart 18: Bacterial equivalent diameters for different cervical conditions(in $\boldsymbol{\mu m})$

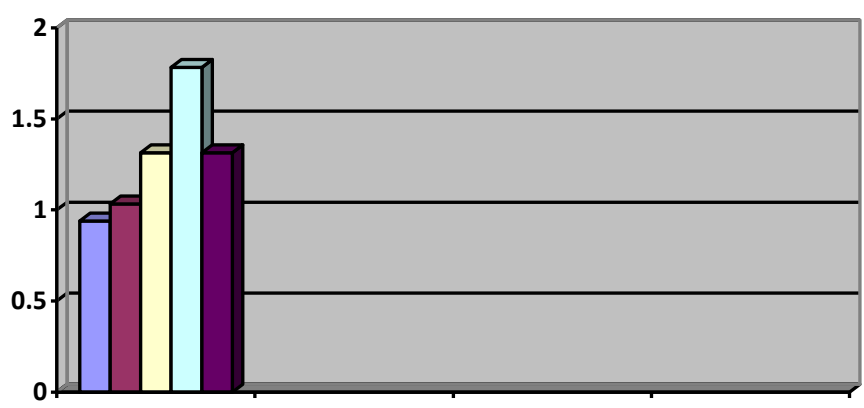

\begin{tabular}{|l|}
$\square$ Normal \\
$\square$ Cervicitis \\
$\square$ Hypertrophied cervix \\
$\square$ Dysplasia \\
$\square$ Neoplasia \\
\hline
\end{tabular}

IV. Conclusion

Based on the above calculation, we will summarise the cytomorphometric parameters by the following range. Area and convex area will be expressed in square of micrometer unit. Perimeter, major axis length, minor axis length, equivalent diameter will be expressed in micrometer unit.

Table 1: Cervical Cytomorphometric ranges:

\begin{tabular}{|l|l|l|}
\hline $\begin{array}{l}\text { Parameters concerning with } \\
\text { the range }\end{array}$ & Cellular Range & Nuclear Range \\
\hline Area $\left(\mu \mathrm{m}^{2}\right)$ & $7.059-219.237$ & $0.0281-0.1433$ \\
\hline Convex area $\left(\mu \mathrm{m}^{2}\right)$ & $7.81-242.5705$ & $0.0293-0.1496$ \\
\hline Perimeter $(\mu \mathrm{m})$ & $11.217-63.19$ & $0.528-1.2118$ \\
\hline Major axis length $(\mu \mathrm{m})$ & $3.8491-21.68$ & $0.187-0.429$ \\
\hline Minor axis length $(\mu \mathrm{m})$ & $2.431-13.4045$ & $0.1763-0.4149$ \\
\hline Equivalent diameter $(\mu \mathrm{m})$ & $2.815-15.8591$ & $0.1317-0.3022$ \\
\hline
\end{tabular}


Table 2: Bacterial Cytomorphometric ranges:

\begin{tabular}{|l|l|}
\hline Parameters concerning with the range & Cellular range \\
\hline Area $\left(\mu \mathrm{m}^{2}\right)$ & $0.8669-2.000078$ \\
\hline Convex area $\left(\mu \mathrm{m}^{2}\right)$ & $0.9591-2.212941$ \\
\hline Perimeter $(\mu \mathrm{m})$ & $3.739-7.10429$ \\
\hline Major axis length $(\mu \mathrm{m})$ & $1.283-2.437785$ \\
\hline Minor axis length $(\mu \mathrm{m})$ & $0.8957-1.27966$ \\
\hline Equivalent diameter $(\mu \mathrm{m})$ & $0.9384-1.782975$ \\
\hline
\end{tabular}

\subsection{Inference on cellular range:}

All the parameters(Area,Convex area,perimeter,major axis length,minor axis length,equivalent diameter) are lowest in neoplasia,highest in hypertrophied cervix.

\subsection{Inference on nuclear range:}

Area and convex areas are lowest in hypertrophied cervix and neoplasia,highest in dysplasia.Perimeter,major axis length,equivalent diameters are lowest in hypertrophied cervix,highest in dysplasia.Minor axis length is lowest in neoplasia,highest in dysplasia.

\subsection{Inference on bacterial range:}

Area,convex area,perimeter,major axis length,equivalent diameters are lowest in normal, highest in dysplasia.Minor axis length is lowest in normal,highest in hypertrophied cervix and neoplasia.

First Author-Agniva Misra,MBBS,MMST,IIT,Kharagpur,agnivam7@ gmail.com

Second author-Suman Chakraborty, PhD, FNASc,FNAE,IIT,Kharagur, suman@ mech.iitkgp.ernet.in

Third author: Aurobindo Rautray,PhD,IIT,Kharagpur,aurobindo.routray @ee.iitkgp.ernet.in

Correspondence Author: Agniva Misra, IIT, Kharagpur, WB, India-721 302; E mail:agnivam7@gmail.com

\section{References}

[1]. Jacques Ferlay,Hai-Rim Shin,Freddie Bray,David Forman,Colin Mathers,Donald Maxwell Parkin,'Estimates of worldwide Burden of cancer in 2008:GLOBOCAN 2008",International Journal of cancer,Volume-127, Issue-12,pages-2893-2917,15 December-2010

[2]. Simona Marcu, Emöke Fülöp, Mariana Tilincă,Antonella Cheşcă," Computerised Cytomorphometry In Cervical Neoplasia”, Annals of RSCB, Vol. XV, Issue 2

[3]. Maud Bessems,Benedict M. Doorschodt,Jan van Marle,Heleen Vreeling,Alfred J. Meijer,Thomas M. van Gulik, "Improved machine perfusion preservation of the non-heart-beating donor rat liver using polysol: A new machine perfusion preservation solution", First published: 19 October 2005,DOI: 10.1002/lt.20502, Volume 11, Issue 11,November 2005,Pages 1379-1388

[4]. Carson, Freida L; Hladik, Christa (2009). Histotechnology: A Self-Instructional Text (3 ed.). Hong Kong: American Society for Clinical Pathology Press. pp. 361-3363. ISBN 978-0-89189-581-7.

[5]. https://www.ndsu.edu/ndsucorelabs/aim-techniquestechnologies-transmitted-light-microscopy 